\title{
Stimulation of Bone Healing with Physical Therapy Modalities by Patients with Delayed Callus
}

\author{
Elizabeta Popova R* and Leonid Ramov \\ Training Implementation Center, Macedonia \\ *Corresponding author: Elizabeta Popova R, Training Implementation Center, Macedonia

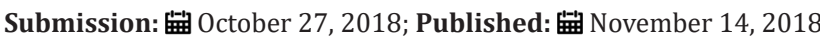

\begin{abstract}
Introduction: Bone repair after fracture can be slowed down for higher reasons: changes in circulation, neuro circulatory dysfunctions, infections, hormonal disorders, primary and metastatic tumors, Patients after surgical treatment come for rehabilitation. The purpose of our research is to represent our experiences in managing the rehabilitation process in the category of patients with bone disorder after fracture and physical medicine practice.

Material and Methods: This work is a synthesis of four ways of treating this group of patients. Patients came for rehabilitation from a parent orthopedic traumatology department or from other institutions of the same type. 53 patients, of different ages divided into four groups by the method of physical treatment and etiology of slow bone remediation were taken for analysis. Group 1-30 patients with fracture and circulatory disturbances, Group 2-20 patients, with fracture and postmenopausal osteoporosis. Group 3-2 patients, with fracture and no formation of callus after 1 year of injury. Group 4-1 patient, fracture-treated surgery and osteosynthesis, and conventional physical therapy without stimulation of callus 6 months after surgery. Assessment of the treatment was scored before and after 2 and 6 months of Physical therapy treatment with measurement of pain, swelling, skin color, range of motion, local osteoporosis by X-ray picture and fracture line signs.
\end{abstract}

Results: Before after two months score for groups were following: 1(95/8.3\%), 2(70/30\%), 3(50/15\%), 4(17/17\%).

Discussion: Patients come for rehabilitation after completing surgical treatment, and the radiographic finding of local posttraumatic osteoporosis is evident. Patients with postmenopausal and systemic osteoporosis are at risk of fracture. Patients treated with bunched transplantation, due to slowing down on fracture, can form callus if it is included after surgery. Stimulation of callus with light therapy, has a science basis.

Conclusion: Successful treatment of conditions with delayed bone healing is necessary to have multidisciplinary treatment, with medication, surgery and conventional physical therapy modalities with effect on bone mass formation.

Keywords: Slow bone healing; Physical therapy modalities

\section{Introduction}

Bone healing may be slowed down or hampered by multiple aetiological factors. Approximately 5-10\% have either delayed or impaired healing $[1,2]$. This understanding of fracture healing has made tremendous strides. To help with the understanding and management of fractures and fracture healing, is the most current concepts in the enhancement of fracture healing [3]. The most common causes of poor differentiation of fibroblasts [4] in osteoblasts in the remodeling phase of fracture repair may be the presence of infection and inflammatory process, poor immobilization, poor quality of bone mass, and lack of building elements minerals and vitamins, hormone deficiency for bone mase formation like in osteoporosis, insufficient circulation in the distal part of the lesion, untreated systemic osteoporosis, etc. [5,6].

Fracture healing involves a complex interplay between several anatomical, biomechanical, and biochemical processes. Skeletal repair, unlike many other tissues, may result in complete restoration of the biochemical and mechanical properties of the injured tissue.
Skeletal tissue has a robust regenerative capacity, the healing process may fail, resulting in delayed healing, non-unions, and malunions [7]. In the Department of Physical Medicine, they come after surgery, either operating or conservative. Physical medicine in Eastern Europe uses physical modalities along with exercises in the process of rehabilitation of patients after a fracture [8-11], but the same is used in the western countries. Early rehabilitation is applied in patients treated with operative treatment and does not contain physical modalities. While those who are treated conservatively, they come for rehabilitation after extraction of gypsum or orthosis. [12].

Physical modalities that we use in bone healing stimulation are: interferential current [8], magnetic field [13], iontophoresis with Calcium chloride, polarization light and low-level laser therapy [14]. The challenge for the treatment is patients with slow bone healing, because there was no callus after their surgical treatment and immobilization, or after conventional treatment with physical 
therapy. The aim of our research is to represent treatment of slow bone healing after fracture deepens of etiology and condition of patient with physical therapy modalities and medicaments.

\section{Material and Methods}

The 53 patients, of different ages divided into four groups by the method of physical treatment and etiology of slow bone remediation were taken for analysis. The patients were divided in four groups, by included criteria. Group 1-30 patients with fracture and circulatory disturbances, Group 2-20 patients, with fracture and postmenopausal osteoporosis. Group 3-2 patients, with fracture and no formation of callus after 1 year of injury, and after bone transplantation. Group 4-1 patient, fracture treated surgery and osteosyntesis and conventional physical therapy without stimulation of callus 6 month after surgery. The evaluation of treatment was scoring before and after 2 and 6 months of Physical therapy treatment with measurement of pain, swelling, skin color, range of motion, local osteoporosis by X-ray picture and fracture line signs. Every positive sign was 1 point. Physical therapy and medication by each group is showing in Table 1 . The significance of treatment before and after two months, and between two and six months is tested with differences of proportion and $\mathrm{p}<0$.

Table 1: Physical therapy modalities and medication.

\begin{tabular}{|c|c|c|}
\hline Group & Physical Therapy Modalities & Medication \\
\hline $\mathrm{N}=30$ & Interferential current, Magnet field & Pentoxifylline, calcitonin, calcium, Vit D/ two months \\
\hline $\mathrm{N}=20$ & Interferential current, Magnet field & calcitonin, calcium, Vit D/ two mounts Bisphosphonates \\
one Year
\end{tabular}

Dosage of physical therapy modalities:

1. Interferential current was applying in region of fracture, 21 days, $15 \mathrm{~min}$. daily,

2. Magnet field therapy, was apply in region of fracture, 21 days, $15 \mathrm{~min}$. daily

3. Low level laser therapy was applying tree times per week, in two area (in elbow region of lymphatic nodules, with screening 5 minutes, in superficial skin region of ulna fracture 5 minutes with screening and 5 minute by points) with ENRAF Nonius device, and power of $50 \mathrm{mw}$, and wave of $920 \mathrm{~nm}$.

Dosage of medicament therapy

1. Tab. Pentoxifylline of $400 \mathrm{mg}, 2 x 1$ daily, 1 month,

2. Spray Calcitonine od 200 IE, 1 daily, 6 weeks,

3. Tab. Calcium $800 \mathrm{mg}, 1$ daily, 2 months/six months depends of group.

Results

Table 2: Evaluation of treatment by Group 1.

\begin{tabular}{|c|c|c|c|}
\hline Clinical Examination & Before Treatment & After 2 Months & After 6 Months \\
\hline Pain & 20 & 2 & 0 \\
\hline Swelling & 30 & 0 & 0 \\
\hline Skin color changes & 30 & 10 & 5 \\
\hline Decrease of joint ROM & 30 & 3 & 0 \\
\hline Local osteoporosis & 30 & 0 & 0 \\
\hline Fracture line & 30 & $15(8.3 \%)$ & $5(6,25 \%)$ \\
\hline Total & $170(94 \%)$ & & \\
\hline
\end{tabular}

Table 3: Evaluation of treatment by Group 2 .

\begin{tabular}{|c|c|c|c|}
\hline Clinical Examination & Before Treatment & After 2 Months & After $\mathbf{6}$ Months \\
\hline Pain & 20 & 0 & 0 \\
\hline
\end{tabular}




\begin{tabular}{|c|c|c|c|}
\hline Swelling & 2 & 0 & 0 \\
\hline Skin color changes & 2 & 15 & 0 \\
\hline Decrease of joint ROM & 20 & 20 & 0 \\
\hline Local osteoporosis & 20 & 0 & 0 \\
\hline Fracture line & 20 & $35(30 \%)$ & $5(4.2 \%)$ \\
\hline Total & $84(70 \%)$ & & 0 \\
\hline
\end{tabular}

Table 4: Evaluation of treatment by Group 3.

\begin{tabular}{|c|c|c|c|}
\hline Clinical examination & Before Treatment & After 2 Months & After 6 Months \\
\hline Pain & 0 & 0 & 0 \\
\hline Swelling & 0 & 0 & 0 \\
\hline Skin color changes & 0 & 0 & 0 \\
\hline Decrease of joint ROM & 2 & 2 & 0 \\
\hline Local osteoporosis & 2 & 0 & 0 \\
\hline Fracture line & 2 & $2(15 \%)$ & $0(0 \%)$ \\
\hline Total & $6(50 \%)$ & & 0 \\
\hline
\end{tabular}

Table 5: Evaluation of treatment by Group 4.

\begin{tabular}{|c|c|c|c|}
\hline Clinical Examination & Before Treatment & After 2 Months & After 6 Months \\
\hline Pain & 0 & 0 & 0 \\
\hline Swelling & 0 & 0 & 0 \\
\hline Skin color changes & 0 & 0 & 0 \\
\hline Decrease of joint ROM & 0 & 0 & 0 \\
\hline Local osteoporosis & 0 & 1 & 0 \\
\hline Fracture line & 1 & $1(17 \%)$ & 0 \\
\hline Total & $1(17 \%)$ & & 0 \\
\hline
\end{tabular}

Table 6: The total effect from treatment.

\begin{tabular}{|c|c|c|}
\hline Before Treatment Max. Score 318 & After 3 Months & After $\mathbf{6}$ Months \\
\hline $161(51 \%)$ & $53(17 \%)$ & $10(3 \%)$ \\
\hline Significance & $\mathrm{T}=8.5 \mathrm{p}<0.05$ & $\mathrm{~T}=0.046 \mathrm{p}>0.05$ \\
\hline
\end{tabular}

Condition of patients were analyzed before treatment, and after two and six months with clinical signs and x-ray, picture. By patient from group 4 was made and CT. Data from effect of treatment is showing in Table 2-6. The effect of treatment is significant before and after 2 months, but it is not significant between 2 and six months.

\section{Discussion}

Normal healing of the skeleton depends on the localization of the fracture line, as well as the type of skeleton, and is usually treated by a traumatic protocol of 4-8 weeks, with immobilization, or 10 days after the surgical treatment begins with physical therapy and rehabilitation. We are following the principles of rehabilitation in our departments [15]. Methods to improve fracture healing are important ways to ensure rapid recovery of patients, which includes return to work, recreation and family life. The group 1 in our research, because of circulatory insufficiency, has local osteoporosis, as a secondary occurrence is a slow formation of the callus. We used medical therapy in consultation with a doctor transfusiologist and for the treatment of local osteoporosis according to our previous experience [16,17]. Medically-known support is one of the common treatments for the successful repair of fracture and local osteoporosis in more frequently consulted studies. Antiresorptive agents such as estrogen, raloxifene, bisphosphonates, and calcitonin inhibit both aspects of bone remodeling, but slow resorption is more than formation [18-20].

Although there are a number of animal studies to support the use of bisphosphonates in fracture healing, there are few studies in humans dedicated to this question, and we have used it by two male patients after transplantation of the chest in the region of slow fracture slowing [21]. We do not use medical support by patients without posttraumatic osteoporosis, usually in our department. Supplementation with calcium and vitamin D is a protocol for the treatment of osteoporosis, and we have used it in treatment to increase bone mass, local and general. Physical therapy modalities 
can increase bone tissue and some of them like interferential current we use in daily practice, special for patient with fracture treated on surgery with inside metal [22]. Magnet field therapy can help too, but to have a effect we need more than 60 days treatment and daily application of minimum $15-30 \mathrm{~min}$. So, it is can be adjuvant but not only simple therapy $[23,24]$.

There are many studies on experimental animals for stimulation of bone mass with low level laser therapy [25]. We use our own way, of application on two areas, on first proximal lymph nodules area and in surface of skin, with careful avoiding a penetration of laser near of internal fixation with metal. We have good formation of bone tissue, but instability of fixation was reason why it was destroyed later. This patient is going to second surgery fixation and after that he was OK. Patients with postmenopausal osteoporosis, find out that they have osteoporosis after a fracture. The treatment of postmenopausal osteoporosis some time is included and follow up at our department [26]. Patients from group 2 were with wrist and arm fracture after fall. Medication in time and physical therapy prevent Sudeck bone Dystrophy. We have our own experience with treatment of sudeck bone Dystrophy, and our treatment is effective in back of function of hand or foot [27].

It is difficult to access the effect of some physical modality, especially because it cannot be use like a single therapy when we have more possibilities and it is not ethical. In all those patients medical gymnastic and work therapy were included too, by individual possibilities and co morbidity of them. In those complex therapy is difficult to make score to evaluate effect, specially when it has no high development Health System like ours. Bone markers and other investigations were made on modern standards. Evaluation with score is showing significant increase of compared before and after two months and compare between 2 months and 6 was not significant, but it proved how long this condition can be preserved.

\section{Conclusion}

Treatment of patient with slow bone healing must be complex and multidisciplinary. Before we make decision to included medical support, we must look for all etiology factors of that condition. Complexity therapy can give good results and support faster callus formation.

\section{References}

1. Hernandez RH, Do TP, Critchlow CW, Dent RE, Jick SS (2012) Patientrelated risk factors for fracture-healing complications in the United Kingdom general practice research database. Acta Orthop 83(6): 653660.

2. Einhorn TA (1995) Enhancement of fracture-healing. J Bone Joint Surg Am 77(6): 940-956.

3. Morshed S (2014) Current options for determining fracture union. Adv Med 708574: 12 .

4. Park SJ, Kim SH, Choi HS, Rhee Y, Lim SK (2009) Fibroblast growth factor 2-induced cytoplasmic asparaginyl-tRNA synthetase promotes survival of osteoblasts by regulating anti-apoptotic PI3K/Akt signaling. Bone 45(5): 994-1003.

5. Bishop JA, Palanca AA, Bellino MJ, Lowenberg DW (2012) Assessment of compromised fracture healing. J Am Acad Orthop Surg 20(5): 273-282.
6. Bhandari M, Guyatt GH, Swiontkowski MF, Tornetta P, Sprague S, et al. (2002) A lack of consensus in the assessment of fracture healing among orthopaedic surgeons. J Orthop Trauma 16(8): 562-566.

7. Marsell R, Einhorn TA (2010) Emerging bone healing therapies. J Orthop Trauma 24(Suppl1): S4-S8.

8. Goats GC (1984) Interferential current therapy. Br J Sports Med 24(2): 87-92.

9. Korenstein R, Somjen D, Fischler H, Binderman I (1984) Capacitative pulsed electric stimulation of bone cells. Induction of cyclic-AMP changes and DNA synthesis. Biochim Biophys Acta 803(4): 302-307.

10. Brighton CT, Okereke E, Pollack SR, Clark CC (1992 In vitro bone-cell response to a capacitively coupled electrical field. The role of field strength, pulse pattern, and duty cycle. Clin Orthop Relat Res (285): 255-262.

11. Brighton CT (1981) The treatment of non-unions with electricity. JBJS 63(5): 847-851.

12. Su B, Newson R, Soljak H, Soljak M (2018) Associations between postoperative rehabilitation of hip fracture and outcomes: national database analysis. BMC Musculoskelet Disord 19(1): 211.

13. Bambini F, Santarelli A, Putignano A, Procaccini M, Orsini G, et al. (2017) Use of supercharged cover screw as static magnetic field generator for bone healing, 2nd part: in vivo enhancement of bone regeneration in rabbits. J Biol Regul Homeost Agents 31(2): 481-485.

14. Sarvestani FK, Dehno NS, Nazhvani SD, Bagheri MH, Abbasi S, et al. (2017) Effect of low-level laser therapy on fracture healing in rabbits. Laser Ther 26(3): 189-193.

15. European Physical and Rehabilitation Medicine Bodies Alliance (2018) White book on physical and rehabilitation medicine in Europe. Chapter 2. Why rehabilitation is needed by individual and society. Eur J Phys Rehabil Med 54(2): 166-176.

16. Baldwin MJ, Policha A, Maldonado T, Hiramoto JS, Honig S, et al. (2017) Novel association between bone mineral density scores and the prevalence of peripheral artery disease in both sexes. Vasc Med 22(1): $13-20$.

17. Popova Ramova E, Shurbevski M (2004) Rehabilitation of patients with trauma and circulatory disorders. Macedonian OrthopedicTraumatology Jouranl 2: 53-57.

18. Popova Ramova E, Poposka A (2008) Physical therapy and medical support by patient with slow bone healing after fracture. First Congress of SOTA with international participation. Belgrade, Serbia, pp. 84-85.

19. Hegde V, Jo JE, Andreopoulou P, Lane JM (2016) Effect of osteoporosis medications on fracture healing. Osteoporos Int 27(3): 861-871.

20. Mashiba T (2011) Morphological analysis of bone dynamics and metabolic bone disease. Histological findings in animal fracture model effects of osteoporosis treatment drugs on fracture healing process. Clin Calcium 21(4): 551-558.

21. Myeroff C, Archdeacon M (2011) Autogenous bone graft: donor sites and techniques. J Bone Joint Surg Am 93(23): 2227-2236.

22. Ganne JM (1988) Stimulation of bone healing with interferential therapy. Aust J Physiother 34 (1): 9-20.

23. Ito H, Shirai Y (2001) The efficacy of un-united tibial fracture treatment using pulsing electromagnetic fields: Relation to biological activity on nonunion bone ends. J Nippon Med Sch 68(2): 149-153.

24. Ramasany B, Chittaranjau S, Ramadass B, Shanmugan NKN (2009) Pulsed electromagnetic field (PEMF) treatment for fracture healing. Curent Orthopaedic Practice 20(1): 1-6.

25. Alves AMM, Fortaleza LM, Filho ALMM, Ferreira DCL, da Costa CLS, et al. (2018) Evaluation of bone repair after application of a norbixin membrane scaffold with and without laser photo bio modulation $(\lambda$ 780nm). Lasers Med Sci 33(7): 1493-1504. 
26. Poposka A, Ramova PE, Jovanovska PM (2012) Questionnaire based screening investigation for risk detection of osteoporosis. Archives of public health 4(2): 30-33.
27. Ramova PE, Poposka A, Ramov L (2013) Medication and appropriate physical therapy of complex regional pain syndrome patients after trauma. Bali Medical Journal (BMJ) 2(2): 59-63. (c) (i) Creative Commons Attribution 4.0 International License

For possible submissions Click Here
Submit Article

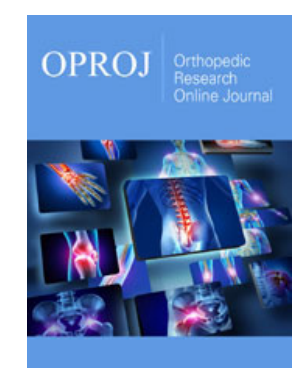

Orthopedic Research Online Journal

\section{Benefits of Publishing with us}

- High-level peer review and editorial services

- Freely accessible online immediately upon publication

- Authors retain the copyright to their work

- Licensing it under a Creative Commons license

- Visibility through different online platforms 